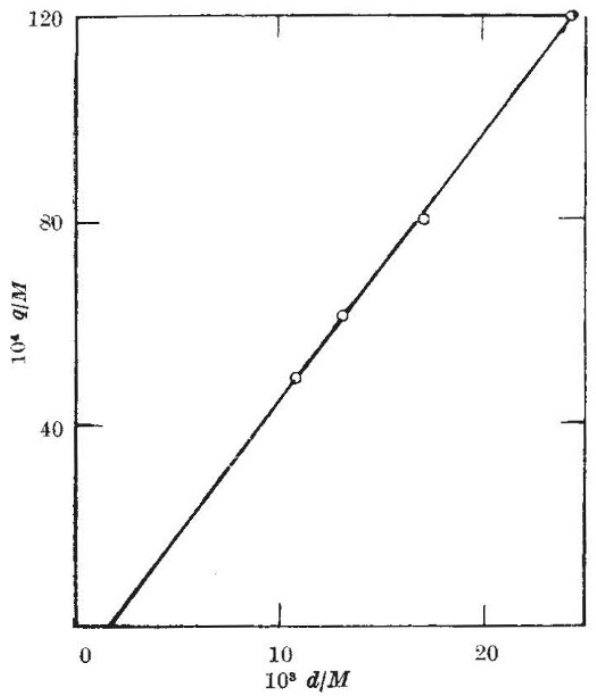

when plotted as $q / M$ against $d / M$, fall very closely on the straight line $q / M=0.528 d / M-0.001$

shown in the accompanying graph.

Broad and Foster ${ }^{1}$ pointed out that relations of this type could be derived theoretically for systems containing tapering capillaries of molecular magnitude, since the volume cut off by an adsorbed molecule which blocks a pore is proportional to the molar volume. Independent confirmation of this relation by other workers is therefore of special interest, and it is to be hoped that future investigators who flnd deviations from Gurwitsch's rule will extend their observations over a wide enough range to test equations of this type.

Chemistry Department,

Royal Holloway College,

University of London, Oct. 26.

${ }^{2}$ Broad, D. W., and Foster, A. G., J. Chem. Soc., 366 (1945).

'J. Russ. 1'hys. Chem. Soc., 47, 805 (1915).
'J. Phys. ('hem., 49, 216 (1945).

Resonance Energies of Acridine and Phenazine

IN the course of an investigation of the heats of combustion of a number of acridine derivatives, the heats of combustion of acridine and phenazine have been determined. From these data the resonance energies of these important heterocyclic nuclei have been calculated for the flrst time.

Acridine was prepared $(a)$ from 5-chloroacridine by dechlorination with hydrogen in the presence of Raney-nickel ${ }^{1}$ and $(b)$ by precipitation with ammonia from B.D.H. acridine hydrochloride. Both specimens, after repeated recrystallization from aqueous alcohol, gave the same heat of combustion. Phenazine was prepared by the method of Eckert and Steiner ${ }^{2}$ and purifled by distillation in superheated steam.

The heats of combustion of acridine and phenazine were found to be $8,797 \cdot 9 \pm 8.9 \mathrm{cal}_{.1} / \mathrm{gm}$. and $8,103 \cdot 7 \pm 8 \cdot 0 \mathrm{cal}_{15} / \mathrm{gm}$. respectively referred to the value $6,324 \mathrm{cal} .15 / \mathrm{gm}$. (in air) for benzoic acid. The molar heats of combustion at constant pressure are thus $1,577 \cdot 8 \pm 1 \cdot 6$ kgm.cal./mole and $1,460.9 \pm 1.4 \mathrm{kgm}$.cal./mole.

Using the rule due to Walden ${ }^{3}$ that $L_{f} / T_{\mathrm{abs}}=13.5$ approximately for most organic substances, the molar heats of fusion of acridine and phenazine are estimated as $5 \cdot 2$ and $6.0 \mathrm{kgm}$.cal., respectivelv. The boiling point of acridine is $346^{\circ}$ and that of phenazine, which had not previously been determined, was found to be $339^{\circ}$. Taking Trouton's constant as 22, the molar heats of vaporization are calculated to be 13.6 and $13.5 \mathrm{kgm}$.cal. respectively.

Thus the heats of combustion of acridine and phenazine in the vapour state are $1,596 \cdot 6 \mathrm{kgm}$.cal. $/ \mathrm{mole}$ and $1,480 \cdot 4 \mathrm{kgm} . \mathrm{cal} . / \mathrm{mol}$ respectively. The heats of formation of carbon dioxide and wate and the heats of dissociation of nitrogen and hydrogen used in the calculation are those used by Pauling ${ }^{5 a}$, as are the bond energies used in the calculation of the heats of formation and of the structures<smiles>c1ccc2nc3ccccc3cc2c1</smiles>

an-1

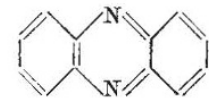

It is found that the resonance energies of acridine and phenazine, referred to these structures, are 106 and $105 \mathrm{kgm}$.cal./mole respectively, which values do not differ by more than the experimental error from the value given by Paulingsb for anthracene (105 kgm.cal./mole). The similarity of the resonance energies of acridine and anthracene suggests that their structures are more closely similar than those of ations of the exaltation of refractivity, v. Auwers and Kraul came to a similar conclusion.

$\begin{array}{lll} & \sum \delta_{\text {Ref. }} & \text { Resonance energy } \\ \text { Benzene } & -0.2 & 39 \text { kgm.cal./mole } \\ \text { Pyridine } & +1.4 & 43 \\ \text { Naphthalene } & +1.85 & 75 \\ \text { Quinoline } & +1.0 & 69 \\ \text { Anthracene } & +4.0 & 105 \\ \text { Acridine } & +3.5 & 106\end{array}$

We are indebted to Dr. D. P. Mellor for his interest in the work. ADRIEN ALBERT.
JOHN B. WILLIS.

Depts. of Organic Chemistry and Chemistry, University of Sydney. Oct. 16.

1 Albert and Willis, $J$. Chem. Soc., in the press.

2 Eckert and Steiner, Monats., 35, 115 (1914).

Walden, Z. Elektrochem., 14, 713 (1908).

"Decker, Ber., 38, 2502 (1905). 1940).

6. Auwers and Kraul, Z. Phys. Chem., 116, 438 (1925).

\section{Ultra-sonic Velocity in Water}

IN view of B. K. Singh's communication on the temperature effect on ultra-sonic velocity in water ${ }^{1}$ it is felt that a brief account of some work done in these laboratories in 1940 may be of interest.

It was known that certain water-alcohol mixtures showed a point of maximum velocity, and it was required to investigate the phe nomenon for a rand of determine the relevant velocities to ancertin 5,000 . In view velocities to an accuracy of better than one part in 5,000. In view of the accuracy required, an absolute method was chosen in which the waves were produced by a quartz crystal driven by an oscillator the frequency of which was known to a few parts in a hundred thousand, (about 5,000 ) measured to the same degree of accuracy.

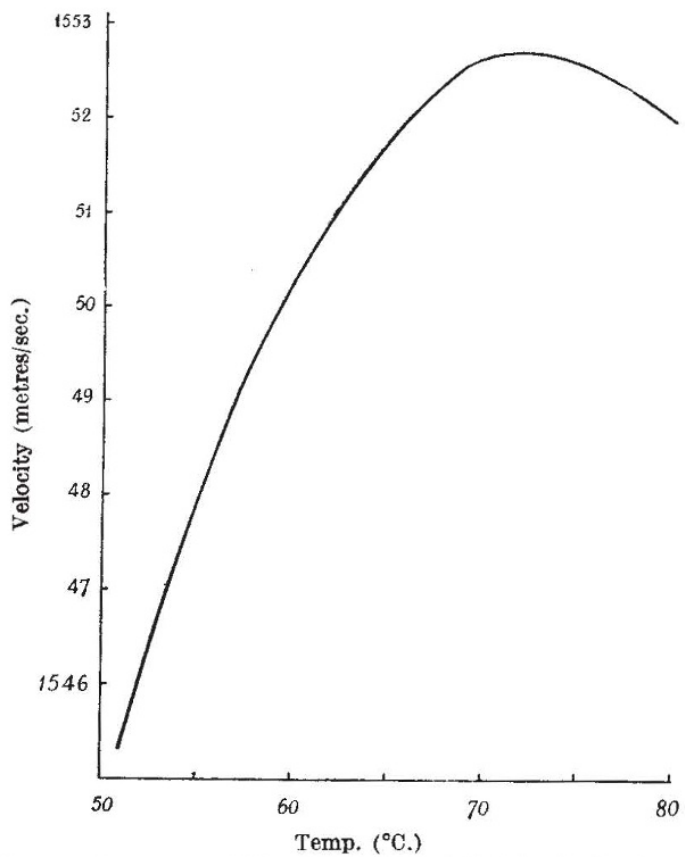

During the course of this work it emerged that distilled water itself (resistivity 0.6 megohms per $\mathrm{cm}^{3}$ at $20^{\circ} \mathrm{C}$.) possessed a maximum velocity and, as seen from the accompanying curve, this is $1552 \cdot 7$ metres

It is hoped at a later date to publish details of the experimental method and of an apparatus based on these results which permits the method and of an apparatus based on these results which permits the accurate measurement of short time-intervals in the range 2-300 micro-secoads. In the meantime, we should like to thank the Director permission for this work to be described and at whose instigation it permission for this

Scophony, Ltd., Wells, Somerset.

P. L. F. JONES.

Nature, 156, 569 (1945)

Rheology of Aqueous Felspar-Pastes

FFLSPAR was not among the thirty substances, mostly minerals, of which the rheology was studied by Freundlich and Jones ${ }^{1} ;$ however, it exhibits noteworthy phenomena which are not peculiar to the sample it exhibits noteworthy phenom

This sample, which had been ground for use in the ceramic industry, whis sample, which had been ground for use in the ceramic industry, was shown microscopically to consist largely of orthoclase and micro-
cline: spectrographic analysis by Dr. $\mathbf{L}$. H. Ahrens conflrmed the cline ; spectrographic analysis by $\mathrm{Dr}$. L. H. Ahrens conflrmed the
essentially potassic nature of the material. The felspar fragments 